\section{ORNL/M .5928}

C/ORNL94-0308
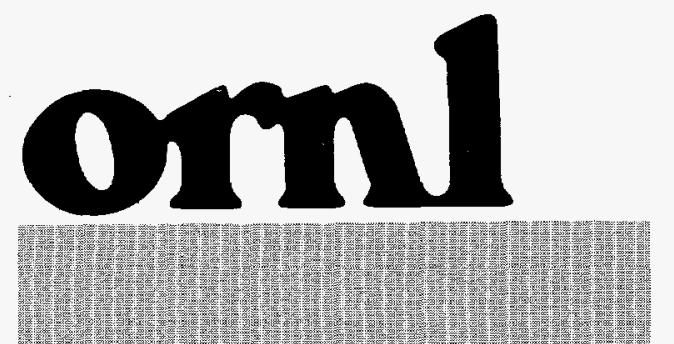

OAK RIDGE NIATIONALE LA: ORATORY
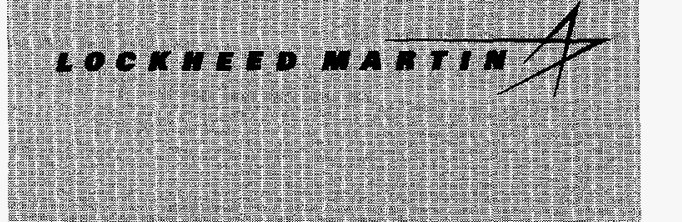

\section{DIAMOND TURNED MASTER MOLDS FOR BULK CASTING OF SOL-GEL SILICA DIFFRACTIVE OPTICAL ELEMENTS}

Final Report for

Cooperative Research and Development Agreement (CRADA) Number ORNL94-0308

\author{
L. C. Maxey \\ Oak Ridge National Laboratory \\ P.O. Box 2008 \\ Oak Ridge, TN 37831-6004 \\ W. Moreshead \\ J. L. Nogues

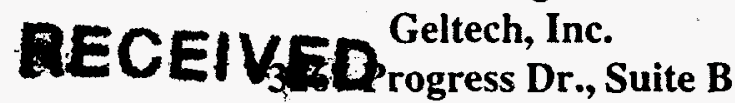 \\ JUN 19 Pag $^{\text {Orlando, FL } 32826}$ \\ OSTI

\section{MASTER}

\author{
Prepared by the \\ OAK RIDGE NATIONAL LABORATORY \\ Oak Ridge, Tennessee 37831-6285 \\ managed by \\ LOCKHEED MARTIN ENERGY RESEARCH \\ for the \\ U. S. DEPARTMENT OF ENERGY \\ under contract DE-AC05-96OR22400
}

Approved for Public Release; distribution is unlimited. 
This report has been reproduced directly from the best available copy.

Available to DOE and DOE contractors from the Office of Scientific and Technical Information, P.O. Box 62, Oak Ridge, TN 37831; prices available from (423) 5768401, FTS 626-8401

Available to the public from the National Technical Information Service, U.S. Department of Commerce, 5285 Port Royal Rd., Springfield, VA 22161.

NTIS price codes-Printed Copy: A03 Microfiche A01

This report was prepared as an account of work sponsored by an agency of the United States Government. Neither the United States Government nor any agency thereof, nor any of their employees, makes any warranty, express or implied, or assumes any legal liability or responsibility for the accuracy, completeness, or usefulness of any information, apparatus, product, or process disclosed, or represents that its use would not infringe privately owned rights. Reference herein to any specific commercial product, process, or service by trade name, trademark, manufacturer, or otherwise, does not necessarily constitute or imply its endorsement, recommendation, or favoring by the United States Government or any agency thereof. The views and opinions of authors expressed herein do not necessarily state or reflect those of the United States Government or any agency thereof. 


\section{DISCLAIMIER}

Portions of this document may be illegible in electronic image products. Images are produced from the best available original document. 
Instrumentation and Controls Division

\title{
DIAMOND TURNED MASTER MOLDS FOR BULK CASTING OF SOL-GEL SILICA DIFFRACTIVE OPTICAL ELEMENTS
}

\author{
L. C. Maxey \\ Oak Ridge National Laboratory \\ Jean-Luc Nogues \\ Bill Moreshead \\ Geltech, Inc.
}

This report was developed under DOE CRADA No. ORNL94-0308

\author{
Prepared by the \\ OAK RIDGE NATIONAL LABORATORY \\ Oak Ridge, Tennessee 37831-6285 \\ managed by \\ LOCKHEED MARTIN ENERGY RESEARCH \\ for the \\ U. S. DEPARTMENT OF ENERGY \\ under contract DE-AC05-96OR22400
}




\section{CONTENTS}

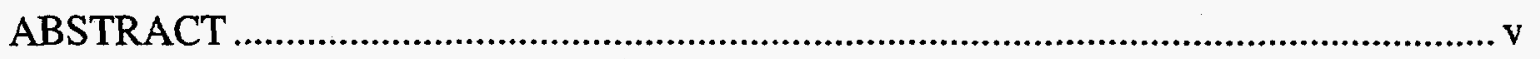

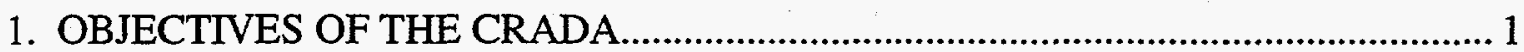

2. ASSURANCE THAT THE CRADA OBJECTIVES HAVE BEEN MET ................... 1

3. BENEFITS TO DOE AND OAK RIDGE NATIONAL LABORATORY .................... 2

4. TECHNICAL DISCUSSION OF WORK ACCOMPLISHED ..................................... 2

5. INTELLECTUAL PROPERTY CONSIDERATIONS ........................................... 5

6. ASSESSMENT OF COMMERCIALIZATION POSSIBILITIES ..............................5

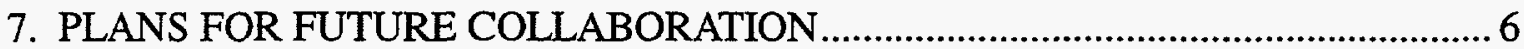

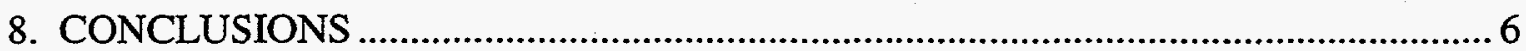

APPENDIX A Interferometry and Stylus Profilometry Data...................................... 7 


\begin{abstract}
This CRADA has combined the resources of a national laboratory and an innovative small company to investigate the production of diffractive lenses in silica glass, using diamond turned master molds. The method for producing these lenses combines the unique characteristics of the sol-gel silica replication process, pioneered by Geltech, with the state-of-the-art diamond turning expertise of the Oak Ridge Centers for Manufacturing Technology (ORCMT).

A conventional lens focuses light by using a curved surface to refract (or bend) the incoming light so that it will form an image. These lenses are usually thick glass elements with one or both surfaces shaped into convex or concave spherical shapes. Traditionally, these lenses are produced by grinding and polishing the glass to the desired shape.

Light can also be focused using the phenomenon of diffraction, rather than refraction. A lens of this type uses precision microscopic surface features to bend the light so that it forms an image. The result is a lens that is thinner and lighter than its refractive counterpart. Production of diffractive lenses requires the ability to accurately produce the precision microscopic features necessary to achieve controlled diffraction. Diffractive lenses have, for the most part, been limited to infra-red applications because the manufacturing technologies available have not enabled their use at visible wavelengths. Except in limited applications, these lenses have remained laboratory curiosities, because they must be individually produced by diamond turning infra-red optical materials.

Geltech's sol-gel silica replication process offers the opportunity to mass produce diffractive lenses in high quality silica glass. These lenses can be produced by diamond turning the necessary precision microscopic surface features into master surfaces that are replicated into intermediate molds. These molds are then used to produce a batch of diffractive lenses using the sol-gel process. The ability to achieve the extremely small feature size required for visible wavelengths is enhanced by the large inherent shrinkage $(60 \%)$ that occurs during the sol-gel replication process. The resulting components are thin, lightweight optical elements tailored to specific imaging requirements.
\end{abstract}




\section{OBJECTIVES OF THE CRADA}

The objective of this CRADA is to investigate the application of single point diamond turned master surfaces for the production of diffractive lenses in sol-gel silica. Each step in the process has limitations that must be understood to assess the viability of this technology. Through this CRADA, the limitations of the diamond turning process, the intermediate mold casting process, and the final sol-gel replication fidelity are assessed.

In this CRADA, diamond turned master surfaces are produced using carefully selected tooling. These master surfaces are replicated in an injection molding process to obtain the quantities of molds required for the sol-gel silica replication process. Finally, the sol-gel silica optics are cast and post -processed.

\section{ASSURANCE THAT THE CRADA OBJECTIVES HAVE BEEN MET}

In this CRADA, a process for economically manufacturing diffractive lenses in high quality silica was comprehensively evaluated. This process achieves thin, lightweight lenses in high quality glass by replicating diamond turned master surfaces in sol-gel silica.

The process was evaluated by developing three designs for diffractive lenses. These designs were for lenses of different focal lengths or optical power. The progressive increase in optical power of the three designs required progressively finer surface features to be achieved. As a result, each design imposed greater challenges on the manufacturing processes.

By pursuing the manufacture of these three lenses, the limitations associated with each step of the manufacturing process were characterized. The program was structured so that the three designs would be pursued in succession, moving to the most challenging design by building upon lessons learned in the previous designs. The result is an objective assessment of the state-of-the-art in this technology. An understanding of the process limitations and methods for overcoming those limitations has emerged.

All of the tasks described under the Scope of Work in the original Statement of Work (SOW) have been performed. The original scope of work was exceeded, by the contractor, to the extent that the tooling used to produce the intermediate molds was changed, requiring production of a second diamond turned master surface for one of the optical designs. In addition, the contractor exceeded the original scope of work by developing a method for directly producing a limited number of plastic intermediate molds through direct diamond turning. These were necessary to obtain diagnostic information on the sol-gel replication process.

The participant exceeded the original scope of work by performing injection molding tasks that were not anticipated in the original scheduling. This represented a significant investment in time, travel and dollars to work with injection molding companies to develop intermediate molds of acceptable quality. 


\section{BENEFITS, TO DOE AND OAK RIDGE NATIONAL LABORATORY}

This CRADA has resulted in the development of manufacturing processes for a class of optical components that did not exist previously. These components are thin, flat, batch processed, high quality glass lenses that develop their optical power through diffraction rather than refraction. The advantages offered by diffractive lenses are that they can be extremely thin and light, while achieving the optical performance of larger lens elements. In addition, the versatility of the manufacturing process allows the lens characteristics to be characterized to achieve specific system performance needs. The DOE benefits from this program by promoting the development of robust, compact, lightweight, bulk processed lenses. These smaller, lighter, high-performance elements will, when fully commercialized, enable reductions in the size, weight and cost of optical systems for a variety of applications related to DOE programs.

Oak Ridge has been a pioneer in single point diamond turning technology since its development in the 1960's. This CRADA has enabled ORNL to maintain and expand its leadership role in diamond turning technology. The processes developed in this CRADA have required working at the very edge of the machine tool limitations. As a result, ORNL has gained experience with new types of diamond tooling to push the limits of the manufacturing process. In addition, the experience gained in the replication process has provided useful insights into replication technologies for producing inexpensive copies of diamond turned master surfaces.

\section{TECHNICAL DISCUSSION OF WORK ACCOMPLISHED}

Closely following the task statements in the SOW, this CRADA was executed in a manner that provided the maximum understanding of the processing limitations and accelerated progress toward commercialization. The original objectives of the CRADA were to produce an $f / 50, f / 25$, and an $f / 10$ lens. Much more aggressive goals were achieved, however. Ultimately an $\mathrm{f} / 15, \mathrm{f} / 10$, and an $\mathrm{f} / 2$ lens were produced.

Through a series of progressively more challenging tasks, the production of bulk cast silica diffractive optics was investigated and refined. The steps for the producing diffractive optic prototypes include: optical design, single point diamond turning, intermediate mold production, sol-gel silica casting, and metrology. Three different optical designs were pursued in this CRADA. Insights gained during the evolution of the CRADA led to a major redesign of the tooling for the production of intermediate molds. An investigative manufacturing process using direct turned molds (i.e. no intermediate molding step) was evaluated as well.

Optic \#1 - f/15 lens: To achieve the progressive goals outlined in the scope of work, while maximizing the progress toward commercialization, an aggressive design was chosen for the first optic. Although a simple lens of modest power $(\mathrm{f} / 50)$ was originally proposed, a more powerful (and more challenging) lens was designed for the first optic. The moderate degree of optical power in the $\mathbf{f} / 15$ lens meant a strong probability that all phases of the manufacture would proceed well. This optic was intended to represent the least challenging "baseline" from which the subsequent optics could be evaluated. A 
functional design was selected that would provide baseline data while seeking to achieve a useful optical element. This planar diffractive optic was designed as an optical corrector for use with an existing lens. The diffractive corrector was designed to compensate the chromatic (i.e. color) aberrations in the companion lens.

The lens design was completed and translated into the machine tool code necessary to produce the diamond turned master surface. The code transformation included the necessary scaling information to account for the shrinkage of $60 \%$ in the final sol-gel silica optic.

Upon receipt by Geltech Inc., the diamond turned master surfaces were transferred to an injection molding facility to produce secondary molds for the sol-gel process. These secondary molds were then used to produce the sol-gel silica optics.

The completed optics were returned to ORNL and tested. The design of the lens (chromatic compensator) did not lend itself to reliable wavefront testing, however interferometric testing did reveal non-rotationally symmetric aberration in the lenses. (A representative interferogram is included in Appendix A). These aberrations were determined to be traceable to the injection molding process. The distortion was deemed sufficient to obfuscate the achromatizing (color correcting) performance of the lens. Subsequent testing of the corrector element with its companion lens was not pursued, to avoid incurring additional fixturing expenses without achieving meaningful results. Profile measurements of the lens, however, revealed that the microscopic features of the diffractive optical surface were being replicated with high fidelity. This indicated that the goals of the research were being met and that the program could proceed to the next level of challenge.

Optic \#2 - f/10 lens: The second optic was designed to have diffraction limited focusing performance (unlike the first optic, which was an achromatic corrector). This would enable the transmitted wavefront of the optic to be accurately measured. The greater optical power of the design of this optic placed greater demands on the diamond turning process to achieve finer features in the master surface.

The diamond turned master surfaces were replicated using injection molding and the resulting molds were measured. The molds were found to have significant distortion and were not deemed to be usable. It was determined that a different tooling design for the injection molding process would significantly improve the intermediate mold quality. New tooling was developed and diamond turned master surfaces were cut into the molding tools. The new tooling was used in an aggressive attempt to solve the injection molding problems.

Despite significant improvements with the new tooling designs, the mold quality was marginal. Without question, the distortion in the molds would dominate all other observable aspects of the replication process. To achieve a reasonable test of the replication process an alternate approach was chosen. Diamond turned molds were cut directly into plastic mold cavities to ensure their geometric fidelity. These were cast with sol gel silica and the resulting optics were measured. The wavefront aberration was under 1 micron peak to valley but still significant (see interferogram in Appendix A).

Optic \#3 - f/2 lens: It was determined that the CRADA objectives could best be met by pursuing the replication of an $\mathrm{f} / 2$ optic without introducing the uncertainties of the injection molding process. It was decided that further investigation of the injection 
molding problems could be pursued outside the scope of the CRADA. The master surfaces for the $\mathrm{f} / 2$ optics were directly turned into plastic molds. Designs for the plastic substrates were chosen to minimize fixturing effects and distortion due to forces encountered during diamond turning.

Ten direct turned polystyrene molds were produced for the sol-gel process. The molds were turned using a 25 micron half-radius tool. Profiles of the molds were measured and showed significant degradation near the edge of the molds. This is evidenced in the progressive decrease in step height from the center to the edge of the mold. These results indicated that the limitations of the 25 micron tool had been reached and that optics of this power would require finer tools to produce.

These molds were then used with the sol gel process to produce the prototypes of the $\mathrm{f} / 2$ diffractive optics. Interruption of the normal processing cycle resulted in a nonstandard process cycle. This may have affected the quality of the finished products. The first prototype lenses showed poor replication of the diffractive structures and could not be effectively tested. The $\mathrm{f} / 2$ optics that were produced achieved a wavefront accuracy similar to that obtained with the $\mathrm{f} / 10$ optics, about 1 micron peak to valley. The form of the error was more uniform, however, than the random errors observed in the $\mathrm{f} / 10$ optics.

\section{Discussion of Results}

Significant insights were obtained during this CRADA regarding the use of single point diamond turning, production of injection molded intermediate molds, and application of direct turned polystyrene molds to the sol-gel process.

Diamond turning considerations: Through the iterative developments of this CRADA, the limitations of the diamond turning process have been identified. Diffractive surfaces differ from those for which diamond turning is traditionally applied. Typical diamond turned surfaces are continuous well defined curves, whereas diffractive surfaces (kinoform type) are discontinuous and defined by a large number of small curves. The controllers for diamond turning machines have a finite amount of memory which limits the number of points available to describe a surface.

The number of points required to adequately describe a kinoform surface can be significantly larger than the number of points required to describe a continuous curved surface. This limit was not a problem in this CRADA but was recognized as a potential production issue for designs that may emerge later on.

A more significant aspect of the diamond turning process is the size and shape of the diamond tools that are used. Typical continuous surfaces are produced by diamond tools that have a circular edge profile. The smallest tool tips obtainable for the production of diffractive kinoform surfaces were tools whose edges were semi-circular (so called "halfradius" tools). These tools were needed to achieve the sharp edges and corners at the kinoform zone transitions.

Half-radius tools with radii as small as 25 microns and as large as 100 microns were evaluated. Procedures for aligning and orienting the tools were developed. Both right hand and left hand tools were evaluated with equal results. Slower feed rates were required with the half-radius tools to achieve similar surface finish characteristics. Although the smallest tool radii produce the best kinoform features, it was determined 
that the feed rates must scale as the inverse square of the radius to maintain good surface finish. For example, a $50 \%$ reduction in tool radius requires a four-fold decrease in feed rate to maintain the same surface finish.

Injection molding: Two different designs for the injection molding tooling were evaluated during this CRADA. More than one molding company was used to generate prototype molds. Ultimately this aspect of the program was and is the most daunting limitation to producing good diffractive optics using the sol-gel silica technology.

There are two conflicting goals in the injection molding process. First, the overall surface flatness must be replicated to within about one-eighth micron for good optical performance. In practice this goal was never achieved. Second, during the injection molding process, the mold must fill uniformly and completely to ensure the accurate replication of the fine structure of the diffractive features. Processing parameters that tended to optimize fine structure were in conflict with the ability to maintain flatness. This remains an area for further optimization.

Direct diamond turned molds: The final optic, the $\mathrm{f} / 10$ lens was produced using polystyrene molds that were directly diamond turned. This provided a means of circumventing the injection molding limitations while evaluating the ability to replicate the very fine structures necessary to achieve $\mathrm{f} / 10$ performance. The polystyrene molds were also viewed as a potential means for manufacturing a higher grade (and more expensive) diffractive optic.

The number of direct turned polystyrene molds was too small for a good statistical sampling, however, the final yield appeared to be lower using this manufacturing approach. Given the difficulties with the injection molding process, the direct turned molds will continue to be of some interest for specific applications if the yield problem can be improved.

\section{INTELLECTUAL PROPERTY CONSIDERATIONS}

The only proprietary information developed by Geltech Inc. during this CRADA relates to their processing technologies and was not divulged to ORNL. No proprietary data was supplied to ORNL during the course of the CRADA. No protected CRADA information developed during the course of this CRADA and no inventions were developed by either party as a result of the CRADA activities.

\section{ASSESSMENT OF COMMERCIALIZATION POSSIBILITIES}

Geltech Inc. is significantly committed to the commercialization of diffractive lenses. As a direct result of this CRADA, the obstacles to commercialization have been reduced. The remaining areas of technical challenge and technical trade-offs have been identified and are being pursued by Geltech at this time. A market opportunity has been identified and a product is being aggressively developed to meet the requirements of that market. 


\section{PLANS FOR FUTURE COLLABORATION}

Geltech Inc. has largely achieved technical independence in the technologies required for the production of diffractive lenses. In the areas of lens design and certain aspects of the diamond turning process, Geltech has expressed interest in a User Facility activity or limited Work for Others program if additional technical collaboration is required.

\section{CONCLUSIONS}

This CRADA exemplifies the type of cooperative research that can enable the advancement of technologies whose technical risk would otherwise impede their progress. The results of this CRADA have enabled significant advances in a new manufacturing technology for diffractive lenses. The research and development activities have strengthened the technical expertise within ORNL and have contributed to the commercialization of new optical components that will benefit DOE programs. Geltech Inc. has been able to make significant progress toward commercialization of a new product as a result of this CRADA. 
APPENDIX A

Interferometry and Stylus Profilometry Data 


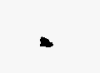




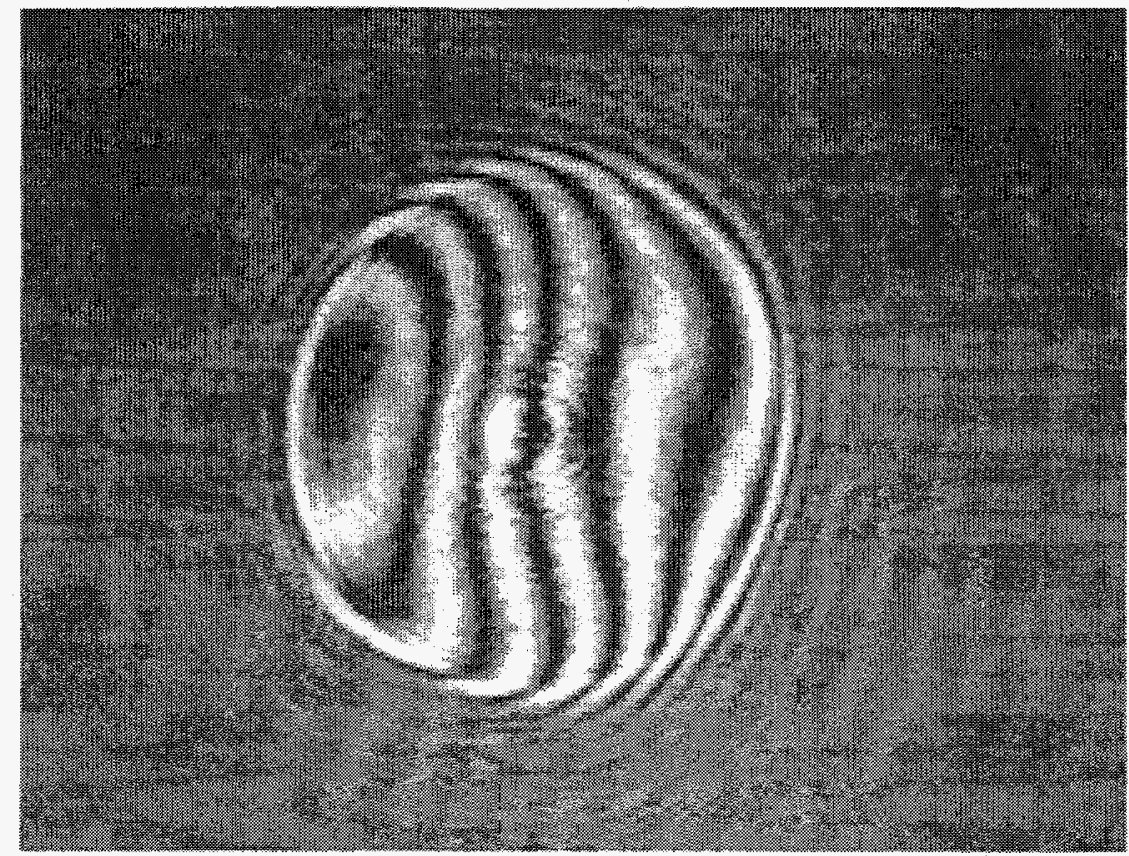

Figure 1. Interferogram of $\mathbf{f} / 15$ optic showing spherical aberration and nonrotationally symmetric errors

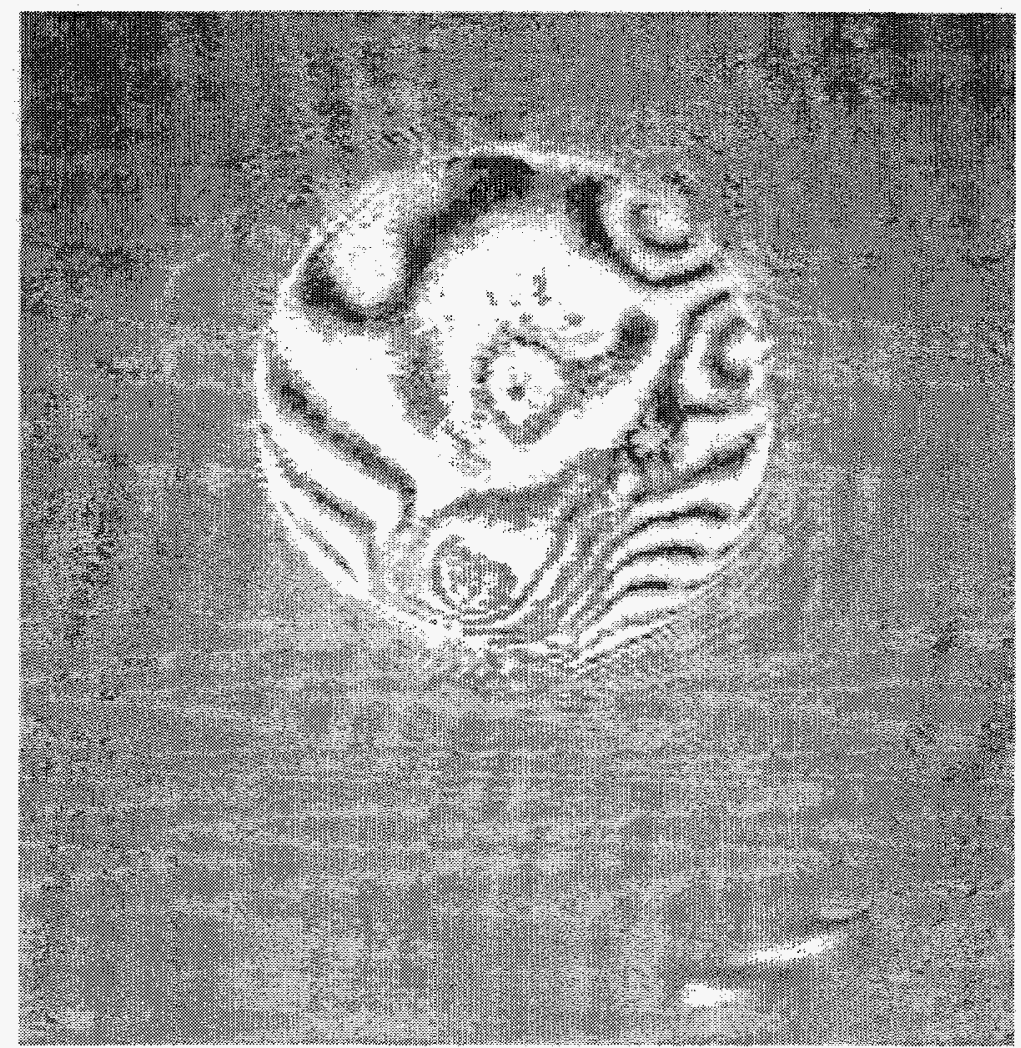

Figure 2. Interferogram of $\mathbf{f} / 10$ optic showing random distortions contributing to peak to valley wavefront error of approximately 1 micron 


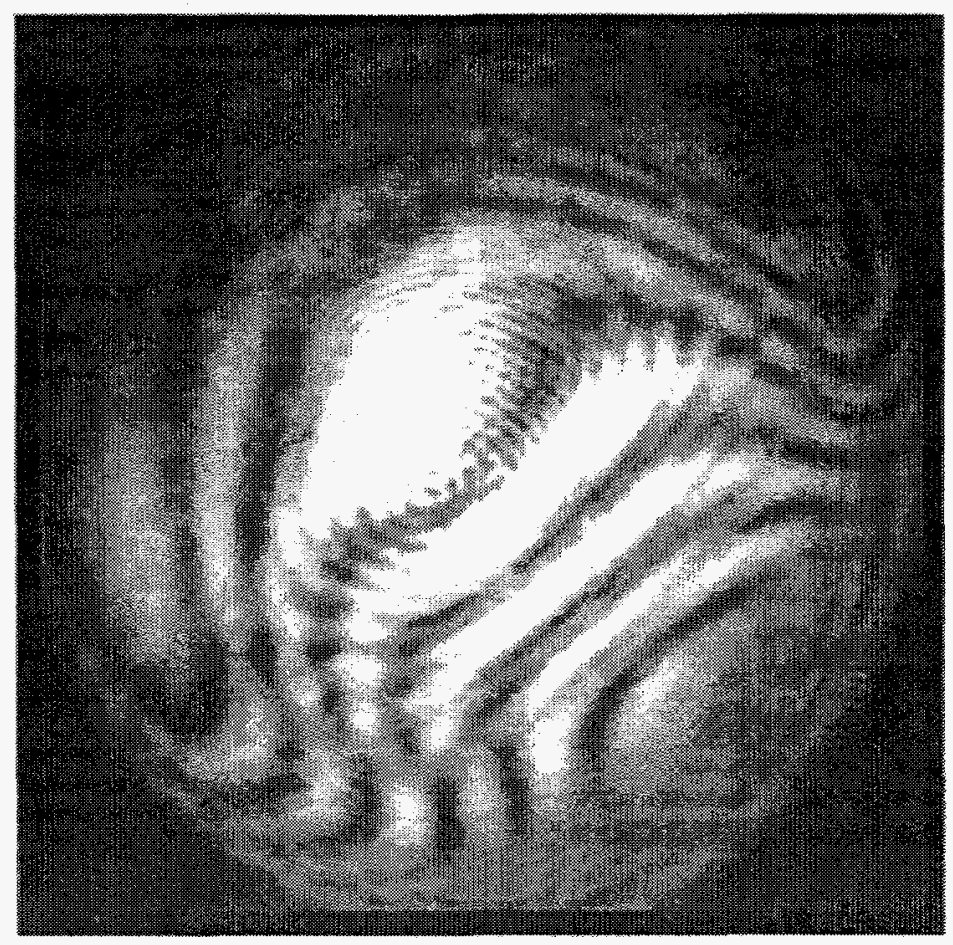

Figure 3. Interferogram of $\mathbf{f} / 2$ optic with smoothly varying 1 micron peak to valley wavefront error

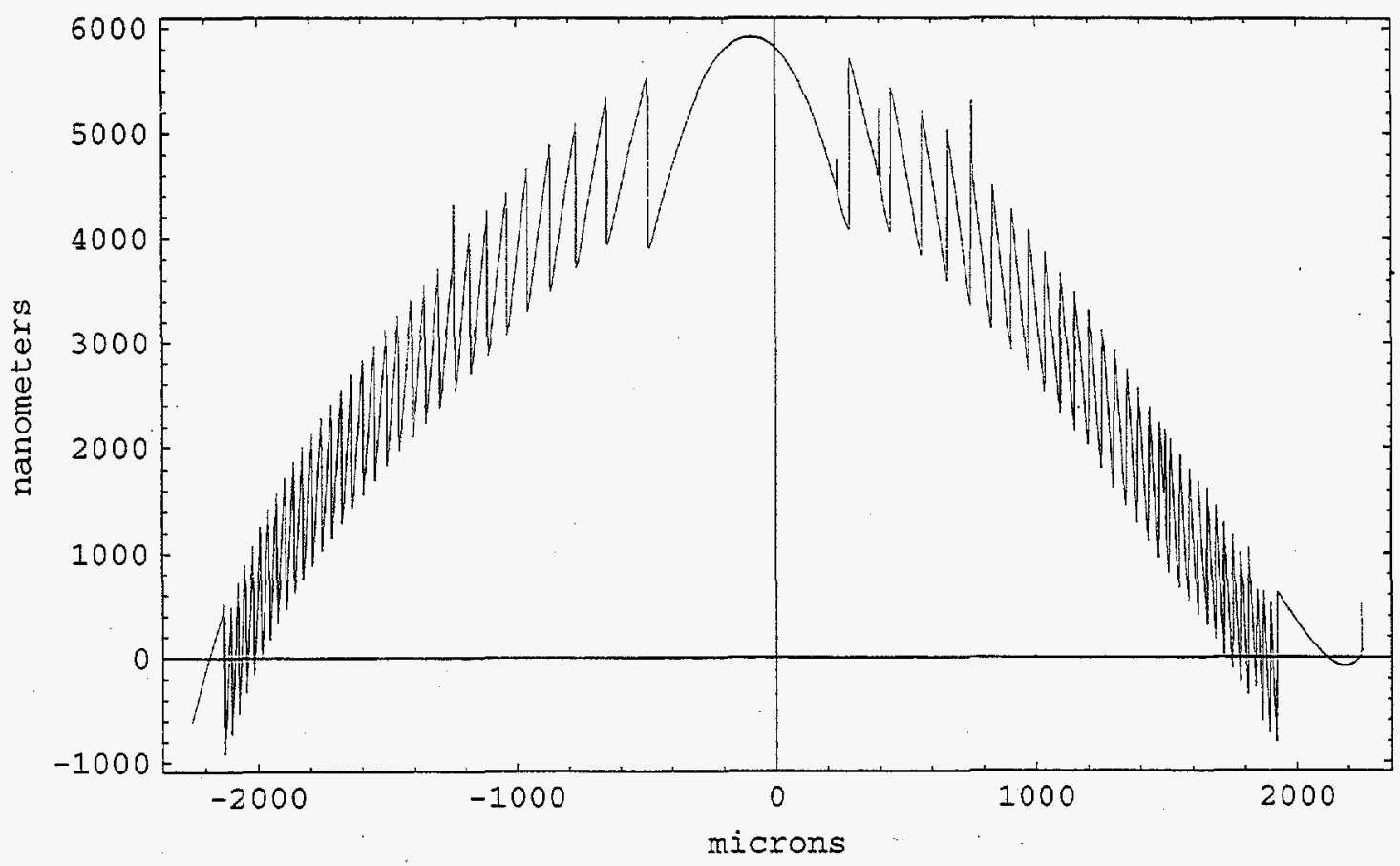

Figures 4. Profiles of $\mathbf{f} / \mathbf{1 5}$ diffractive optic surface 


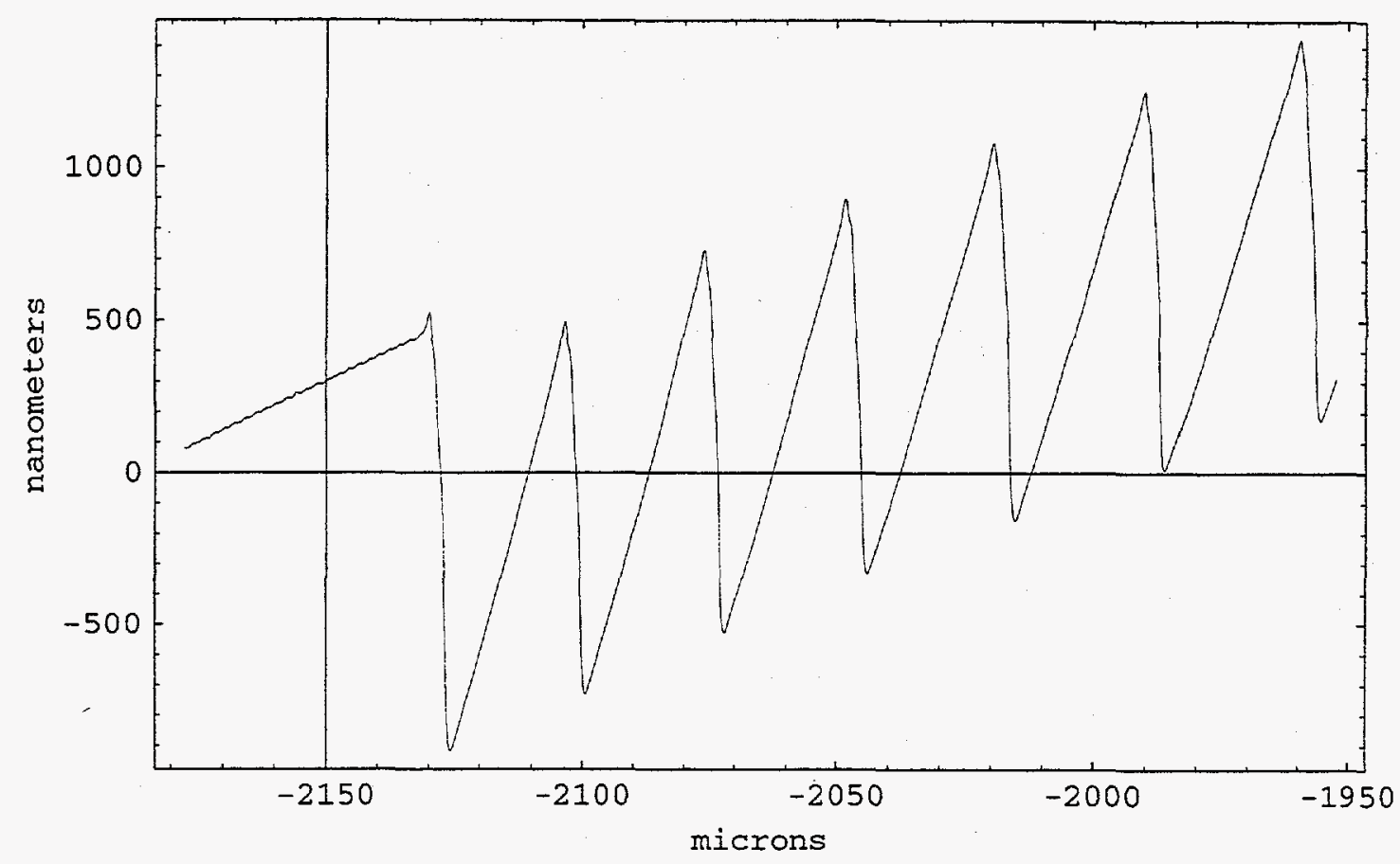

Figures 5. Profiles of $\mathbf{f} / 15$ diffractive optic surface

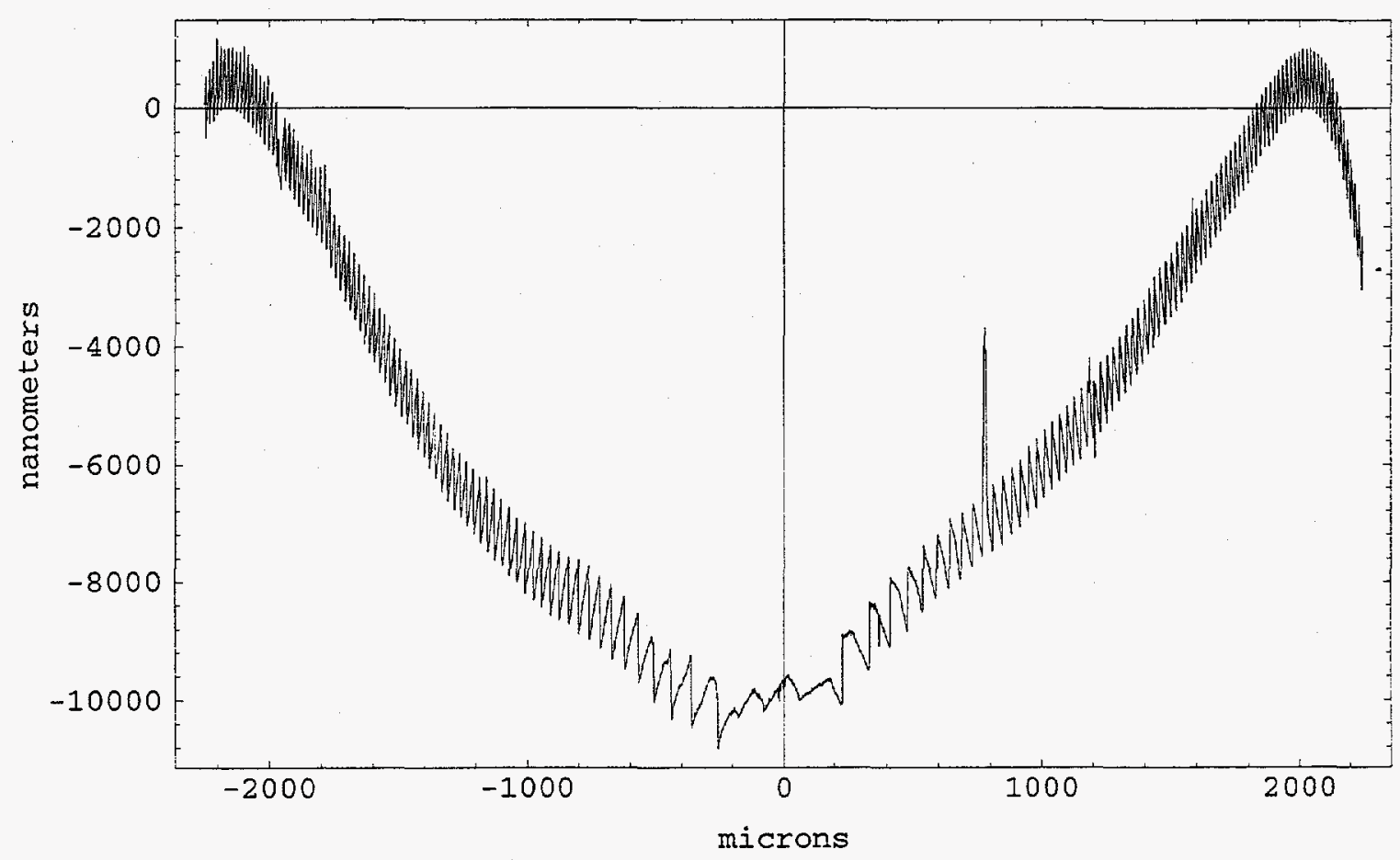

Figures 6. Profiles of $\mathbf{f} / \mathbf{1 0}$ mold surface for producing diffractive optics 


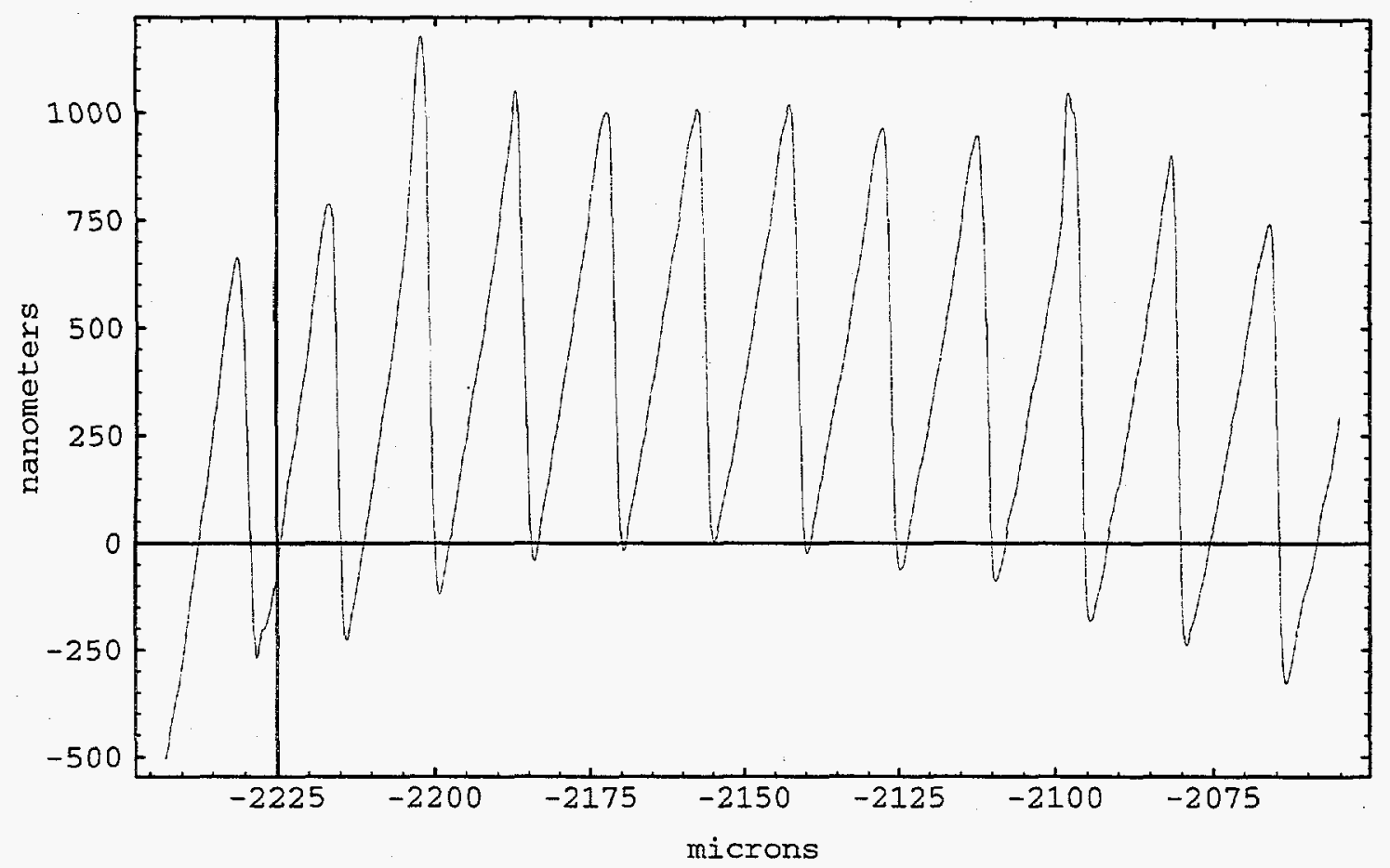

Figures 7. Profiles of $\mathbf{f} / \mathbf{1 0}$ mold surface for producing diffractive optics

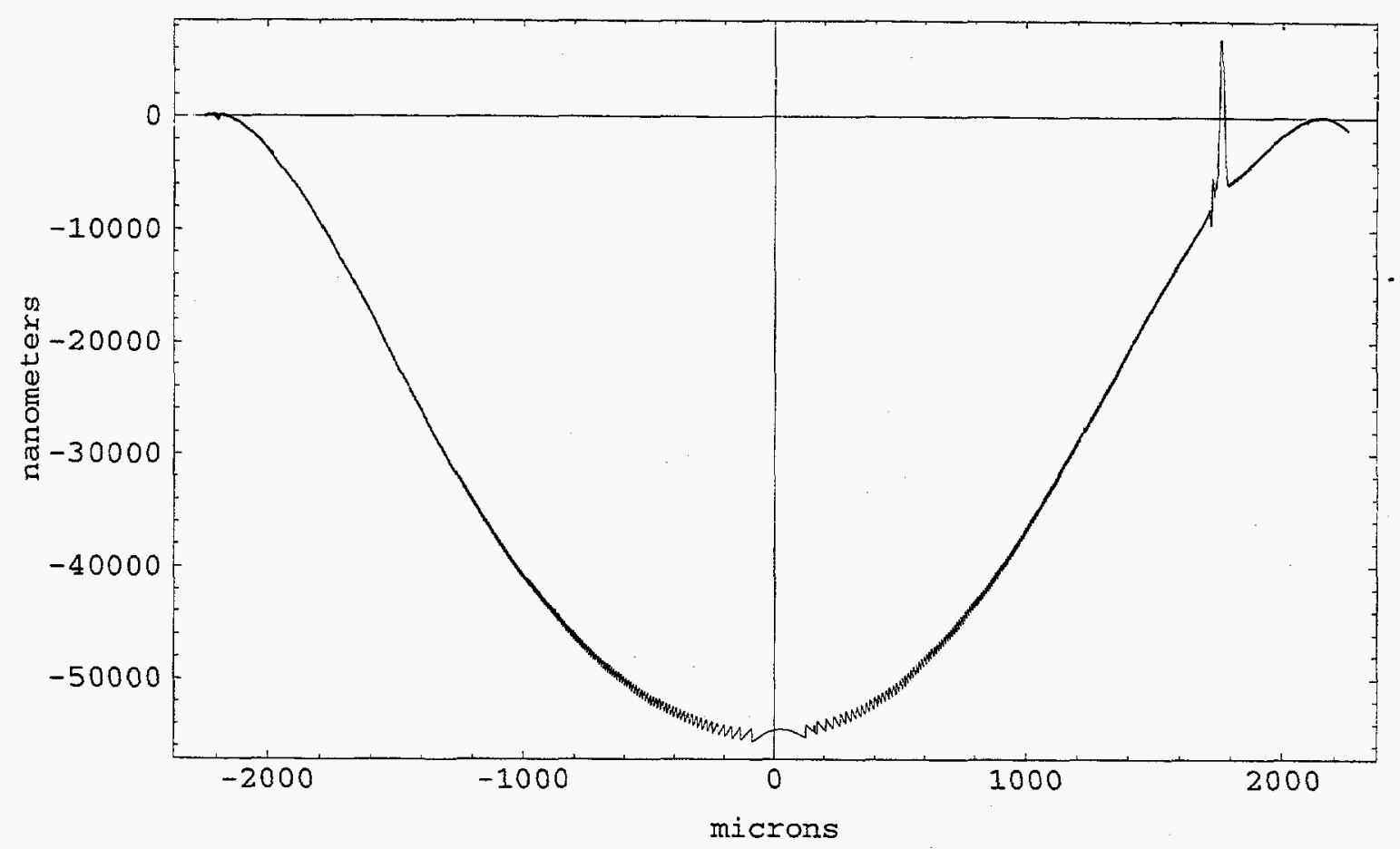

Figures 8. Profiles of $\mathbf{f} / \mathbf{2}$ mold surface, demonstrating significant rolloff in step height near the edge of the optic 


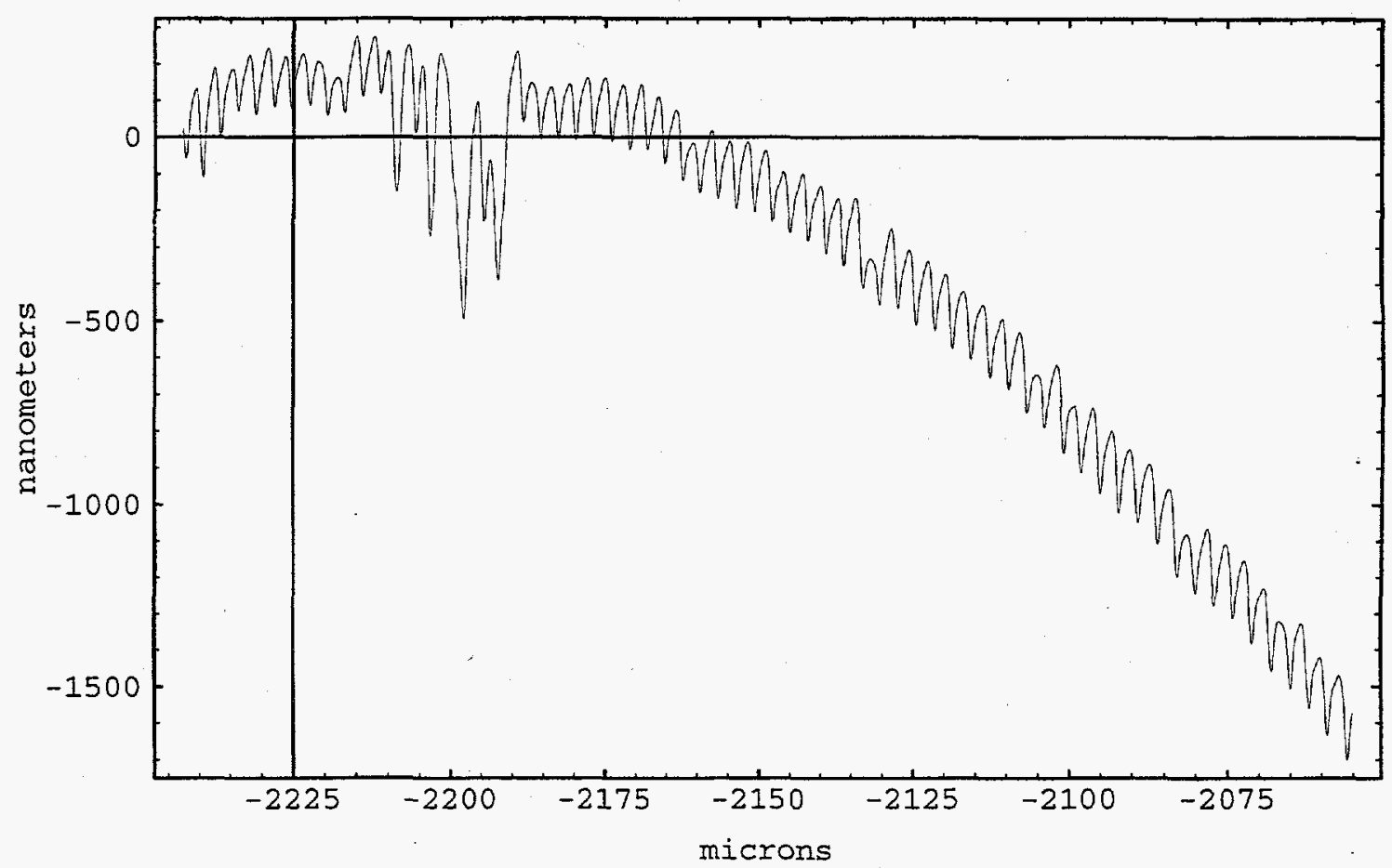

Figures 9. Profiles of $\mathbf{f} / \mathbf{2}$ mold surface, demonstrating significant rolloff in step height near the edge of the optic 


\section{DISTRIBUTION}

1. B. B. Bovee, 701SCA, MS-8242

2. J. P. Cunningham, $9102-2$, MS-8039

3. L. B. Dunlap, 5002, MS-6014

4. B. M. Evans, $9102-2$, MS-8039

5. E. C. Fox, 9201-3, MS-8063

6. R. G. Gilliland, $4500 \mathrm{~N}, \mathrm{MS}-6248$

7. P. L. Gorman, DOE ORNL Site Office, $4500 \mathrm{~N}, \mathrm{MS}-6269$

8. S. D. Hamel, DOE Office of Patent Counsel, 701SCA, MS-8243

9. J. T. Hill, 9737, MS-8091

10. B. S. Hoffheins, 3500 , MS- 6004

11. A. J. Luffman, Office of Science Technology Partnerships, 5002, MS-6416

12-18. L. C. Maxey, 3500, MS-6004

19. D. W. McDonald, 3500 , MS-6004

20. A. C. Miller, $9102-2$, MS-8039

21. G. N. Miller, 3500 , MS-6004

22. K. A. Moore, 3500 , MS-6004

23. W. Moreshead, Geltech, Inc., 3267 Progress Dr., Suite B, Orlando, FL 32826

24. J. L. Nogues, Geltech, Inc., 3267 Progress Dr., Suite B, Orlando, FL 32826

25. W. P. Painter, 5002, MS-6416

26. W. M. Polansky, Director, Advanced Energy Projects and Technology Research, DOE, 19901 Germantown Rd., Germantown, MD 20874

27. J. E. Rogers, 3500 , MS-6004

28. T. M. Rosseel, 5002, MS-6416

29. J. W. Shepherd, 5002 , MS- 6416

30. J. O. Stiegler, 2024, MS-6017

31. C. A. Valentine, OTT Business Manager, 701SCA, MS-8242

32. Central Research Library, 4500 N, MS-6191

33. DOE-WFO, Federal Bldg., MS-G209

34. Laboratory Records-RC, $4500 \mathrm{~N}, \mathrm{MS}-6285$

35-36. Office of Scientific and Technical Information, P.O. Box 62, Oak Ridge, TN 37831 